\title{
Monitoring and prediction in early warning systems for rapid mass movements
}

\author{
M. Stähli ${ }^{1}$, M. Sättele ${ }^{2}$, C. Huggel ${ }^{3}$, B. W. McArdell ${ }^{1}$, P. Lehmann ${ }^{4}$, A. Van Herwijnen ${ }^{2}$, A. Berne ${ }^{5}$, M. Schleiss ${ }^{5, *}$, \\ A. Ferrari ${ }^{6}$, A. $\operatorname{Kos}^{7, * *}$, D. Or ${ }^{4}$, and S. M. Springman ${ }^{7}$ \\ ${ }^{1}$ Swiss Federal Institute for Forest, Snow and Landscape Research WSL, Birmensdorf, Switzerland \\ ${ }^{2}$ WSL Institute for Snow and Avalanche Research SLF, Davos Dorf, Switzerland \\ ${ }^{3}$ Department of Geography, University of Zurich, Zurich, Switzerland \\ ${ }^{4}$ Soil and Terrestrial Environmental Physics, ETH Zurich, Zurich, Switzerland \\ ${ }^{5}$ Environmental Remote Sensing Laboratory, EPF Lausanne, Lausanne, Switzerland \\ ${ }^{6}$ Soil Mechanics Laboratory, EPF Lausanne, Lausanne, Switzerland \\ ${ }^{7}$ Institute for Geotechnical Engineering, ETH Zurich, Zurich, Switzerland \\ *now at: Civil and Environmental Engineering, Princeton University, Princeton, USA \\ ** now at: Terrasense Switzerland Ltd, Werdenberg, Switzerland
}

Correspondence to: M. Stähli (manfred.staehli@wsl.ch)

Received: 21 October 2014 - Published in Nat. Hazards Earth Syst. Sci. Discuss.: 27 November 2014

Revised: 11 March 2015 - Accepted: 28 March 2015 - Published: 24 April 2015

\begin{abstract}
Rapid mass movements (RMM) pose a substantial risk to people and infrastructure. Reliable and cost-efficient measures have to be taken to reduce this risk. One of these measures includes establishing and advancing the state of practice in the application of early warning systems (EWSs). EWSs have been developed during the past decades and are rapidly increasing. In this paper, we focus on the technical part of EWSs, i.e., the prediction and timely recognition of imminent hazards, as well as on monitoring slopes at risk and released mass movements. Recent innovations in assessing spatial precipitation, monitoring and precursors of the triggering and deformation of RMM offer new opportunities for next-generation EWSs. However, technical advancement can only be transferred into more reliable, operational EWSs with an adequate well-instructed dedicated staff. To this end, an intense dialog between scientists, engineers and those in charge of warning, as well as further experience with new comprehensive prototype systems jointly operated by scientists and practitioners, will be essential.
\end{abstract}

\section{Introduction}

A sustainable risk management approach is preventive and includes reliable and cost-efficient risk mitigation measures. During the last decades, early warning systems (EWSs) for rapid mass movements (RMM) have become an essential element of integral risk management worldwide (Glade and Nadim, 2014). Although they span a wide range of spatial scales and technological complexities, their ultimate goal is always the same: to alert people to imminent hazards and allow them to get to safety. Numerous EWSs worldwide have been followed up by researchers and reported in the scientific literature (Fig. 1). Active systems and state-of-the-art technology installed for gravity-driven mass movement processes are summarized in Bell et al. (2010). The United Nations Environment Programme (UNEP, 2012) provided a worldwide compilation of EWSs for different natural hazard processes. Baum and Godt (2010) summarized EWSs of shallow landslides and debris flows in the USA. In Austria, an overview of EWSs for snow avalanche and landslide processes was published by the Forestry Torrent and Avalanche Control (Forsttechnischer Dienst für Wildbach- und Lawinenverbauung, 2008). A recent overview of operational landslide EWSs in Europe was assembled for the EU FP7 project SafeLand 


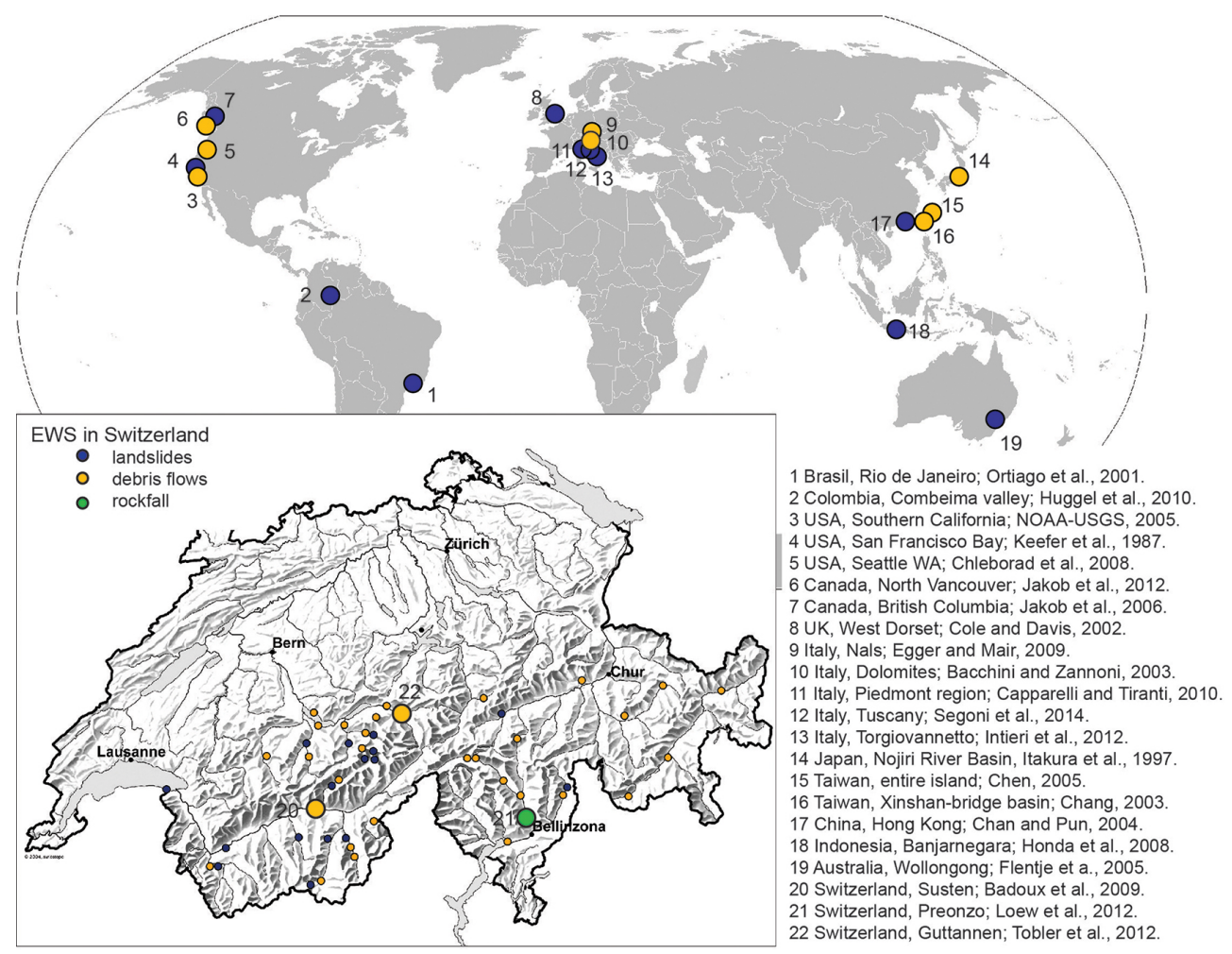

Figure 1. Map of selected EWS sites - worldwide and in Switzerland - reported in literature.

(Michoud et al., 2013). Villagrán de León et al. (2013) presented a comparative review and discussed differences of warning and alarm frameworks. Successful implementation of EWSs has also been reported for less-developed countries (Huggel et al., 2010).

Switzerland is a prominent example of a country that is prone to damage caused by RMM due to its topographic disposition. Here, the first automatic EWS for snow avalanches was operated in Mahnkinn in 1937 (Sättele and Meier, 2013) to detect spontaneous snow avalanches above an endangered railroad. Today, EWSs are operated in a diversity of designs for various natural hazard processes. A collection of site-specific EWSs was first published by Eyer et al. (1998). Gubler (2000) described system components and experiences of site-specific EWSs for snow avalanches, mudflows and rock fall. Hegg and Rhyner (2007) provided an overview of national warning products in Switzerland. Recently a common information platform for natural hazards was established to provide warning information from four Swiss warning centers in an integrated manner (Heil et al., 2014).

Integral EWSs typically include four key elements (UNEP, 2012): (a) a comprehensive assessment of the risks, (b) a sensor-based monitoring and warning system, (c) a plan for the dissemination of alerts and (d) strategies for the response of the people at risk. The present review article only discusses the current state of the scientific and technical part of EWSs, i.e., the prediction and timely recognition of im- minent hazards and released mass movements, as well as the monitoring of slopes at risk. Herein we focus on landslides, debris flows and snow avalanches with speeds on the order of meters per second. Many of our statements are general and apply also to other types of RMM, such as rock falls and ice avalanches. The issue of disseminating warnings and response is deliberately not considered here. The paper aims at providing a useful basis for the design of next-generation EWSs.

\section{Types and characteristics of existing early warning systems}

A recent study (Sättele et al., 2012) investigated the reliability of EWSs, their comparability to alternative protection measures and their cost-effectiveness. More than 50 active EWSs in Switzerland were identified and analyzed to derive a classification of EWSs. The study suggests that EWSs can be classified into (i) alarm, (ii) warning and (iii) forecasting systems. Pure monitoring systems, e.g., for research purposes, however, do not actively issue warning information and are, accordingly, not considered as EWSs.

- Alarm systems detect process parameters of ongoing hazard events to initiate an alarm automatically, e.g., in the form of red flashing lights accompanied by sirens. The accuracy of the prediction is high, but the lead 

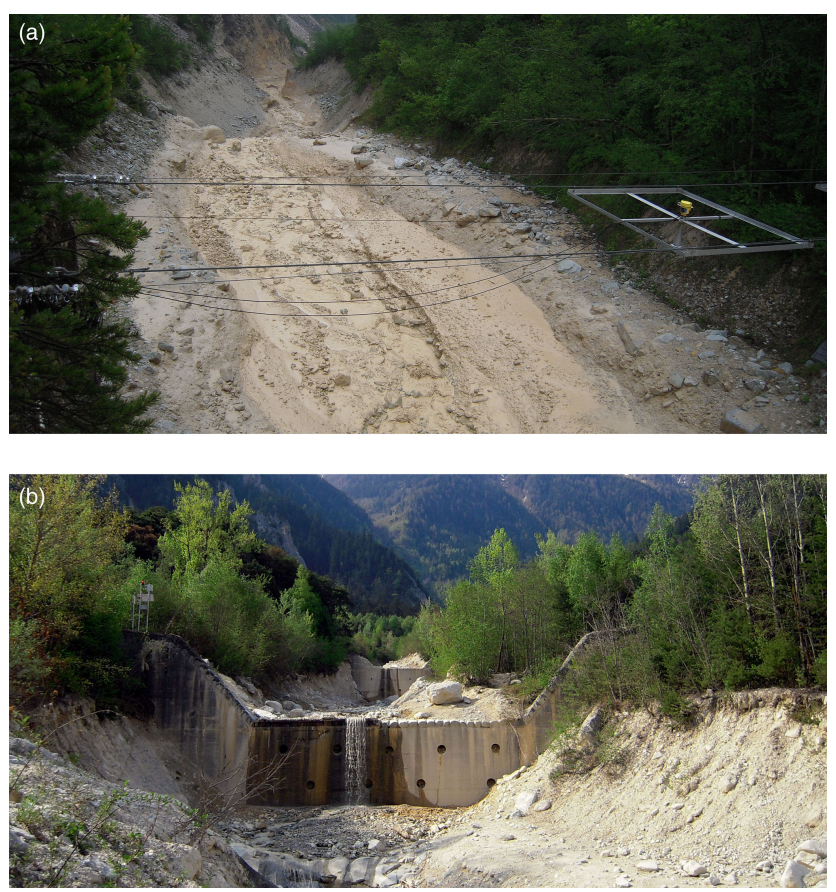

Figure 2. Debris-flow EWS Illgraben (Canton VS, Switzerland): (a) the debris-flow detection system in the upper part of the catchment (b) the lower part of the catchment with warning system.

time is short. The alarm decision is based on a predefined threshold. One of the first such systems was implemented in the region of the Nojiri River, Japan (Itakura et al., 1997; Fig. 1). A more recent prominent example is the Illgraben debris-flow alarm system in Canton Valais, which protects people crossing the channel from debris flows as they are detected (Fig. 2). Here, sensors are installed in the upper catchment to detect ground vibrations and an increase in flow depth that indicate an ongoing debris flow, to trigger an alarm in the form of flashing lights and audible signals at channel crossings further downstream, and to send text messages to local hazard managers (Badoux et al., 2009). Alarm systems are often installed to prevent damages caused by natural hazard processes that may be rapidly triggered such as debris flows, snow avalanches, glacier lake outburst floods and rock falls.

- Warning systems aim to detect significant changes in the environment (time-dependent factors determining susceptibility with respect to mass release), e.g., crack opening, availability of loose debris material and potential triggering events (e.g., heavy rain), before the release occurs and thus allow experts to analyze the situation and implement appropriate intervention measures. The information content of the data is often lower in this early stage, but the lead time is extended. The initial alert is based on predefined thresholds. In Preonzo (Ti- cino, southern Switzerland), for instance, a warning system was installed to forecast an emerging rockfall. The velocities of the movement of a large body of rock at the top of the hillslope were measured, and an alert was sent when predefined thresholds were exceeded (Loew et al., 2012). Warning systems are mainly used for processes with progressive stages of failure, such as rock slides and deep-seated landslides.

- Forecasting systems predict the level of danger of a RMM process, typically at the regional scale and at regular intervals. In contrast to warning systems, the data interpretation is not based on a threshold but is conducted on a regular basis, e.g., daily. Experts analyze sensor data and consult models to forecast the regional danger levels, which are communicated widely in a bulletin. For example, the WSL Institute for Snow and Avalanche Research operates a snow avalanche forecasting system and publishes a daily bulletin to predict the degree of avalanche danger for the next day (Rhyner, 2007). Another well-known example of a forecasting system was operated in the San Francisco Bay region (Keefer et al., 1987) for the early warning of landslides. It was a pioneer system based on relations between rainfall and landslide initiation and a geologic assessment of landslide susceptibility. Similar systems are operated in many regions worldwide for other mass movement processes (e.g., Bell et al., 2010).

Independent of the classification of an EWS, it must fulfill the following criteria (e.g., Michoud et al., 2013; Glantz, 2003; UN/ISDR, 2006):

- Easy to implement: limited complexity of the technical system, as well as a thorough instruction of the people responsible (often laypeople), is essential.

- Comprehensible and manageable: thresholds (e.g., precipitation amount or runoff levels) have to be evident and comprehensible for those in charge of issuing warnings.

- Redundancy: the EWS may not depend on single sensors and transmission lines but must be based on a range of different installations (and complementary parameters, if possible).

- Precision: the critical property defining the hazard level must be measured with sufficient precision.

- Autonomy (electricity and data transfer): the system must need minimal maintenance and be functional in remote regions.

- Robustness: the instruments must be able to resist the expected range of environmental conditions and, to some extent, mechanical perturbation. 
Table 1. Technologies typically used in current EWSs and proposed for future EWSs.

\begin{tabular}{|c|c|c|c|c|}
\hline Observed parameter & & Technology & Type of EWS & References \\
\hline \multirow[t]{2}{*}{ Precipitation } & Sum, intensity & Rain gauge & All & \\
\hline & & Precipitation radar & Forecasting systems & Panziera et al. (2011) \\
\hline \multirow[t]{2}{*}{ Snow cover } & Depth & & Forecasting systems & \\
\hline & Wetness & & Forecasting systems & \\
\hline \multirow[t]{3}{*}{ Soil moisture } & Water content & TDR & Forecasting systems & \\
\hline & Water suction/pressure & Tensiometer & Forecasting systems & \\
\hline & Groundwater table & Piezometer & Forecasting systems & \\
\hline \multirow[t]{6}{*}{ Rock/soil surface } & Precursor of failure & Acoustic sensors & Warning system & Michlmayr et al. (2013) \\
\hline & Displacement & Trigger line & Alarm systems & \\
\hline & & Extensometer, total stations & Warning systems & \\
\hline & & Inclinometer & Warning systems & \\
\hline & & Ground-based radar interferometry & Warning systems & Caduff et al. (2015) \\
\hline & & Satellite-based radar interferometry & Warning systems & Wegmüller et al. (2013) \\
\hline \multirow{4}{*}{$\begin{array}{l}\text { Triggered mass } \\
\text { movement }\end{array}$} & Vibration & Geophone & Alarm systems & \\
\hline & & Seismometer & Alarm systems & \\
\hline & Flow surface height & Radar & Alarm systems & \\
\hline & Flow characteristics & Video & Alarm and warning systems & \\
\hline
\end{tabular}

- Affordable price: the costs of acquisition and operation have to be balanced with the expected risk reduction.

Researchers and practitioners in Switzerland discussed the needs of future EWSs in a workshop in January 2013 with natural hazard experts responsible for the management of the debris-flow EWS Spreitgraben (Tobler et al., 2012) and for several rock-fall EWSs in central Switzerland (Wegmüller et al., 2013). The practitioners stated that they have to ensure that the specific technical components of such systems are suitable for the planned intervention measures. They have also experienced that a technical design is of low value without a clear distribution of responsibilities and organizational tasks enabling the effective management of emergencies.

A further concern for these experts was the abundance of sufficient information required to provide a comprehensive and complete risk assessment. However, more measurements and data do not necessarily make risk management easier. Often, it is not the number of data but the understanding of the processes and the complex relationships between process measurements and probability of the onset of rapid mass movement that limits the success of an EWS.

\section{Limitations of current EWSs}

The range of technologies used in current EWSs to monitor environmental variables for recognizing critical states is very broad (Table 1). For each EWS, the specific choice of instrumentation depends on the type of imminent hazard, the area at risk, the know-how of the responsible authorities and the trade-off between costs and risk reduction.

Common for most of the systems are measurements of precipitation, typically recorded at local weather stations.
These measurements are often used to issue alarms as soon as site-specific thresholds of total amount and intensity are exceeded (e.g., Guzzetti et al., 2008). In alarm systems, often some combination, e.g., of geophones, seismometers, trigger lines and flow-height sensors, is set up to detect the release or the passage of debris flows or rock falls (Sättele and Meier, 2013). For warning systems, in contrast, it is common to deploy sensors that depict the onset of movement, such as extensometers, inclinometers or terrestrial radar systems (Caduff et al., 2015; Sättele and Meier, 2013). Finally, continuous measurements of soil water pressure, snow depth and spatial precipitation are used in forecast systems (Lehning et al., 1998).

In spite of the continuous worldwide progress of these technologies and the increasing experience obtained by operators and managers, we still face inherent shortcomings and limitations of current EWSs:

1. Current EWSs are sometimes too closely focused on simple thresholds. Thresholds (e.g., of measured precipitation) for the release of RMMs cannot be defined universally, but must be adapted to local conditions. Defining local thresholds and corresponding warning levels is an iterative process that requires a long-term record of events. Newly installed EWSs or EWSs set up to protect against only rare events do not provide a sufficient basis for defining plausible thresholds. In addition, thresholds can change over time, e.g., as critical geotechnical properties are changing (e.g., degrading permafrost), or as a consequence of previous events (e.g., slope erosion or raised saturation degree in the ground after a wet winter). 
2. The observations used in current EWSs are often not representative for site-specific processes. In many cases, the available measurements (e.g., rainfall data) used for the early warning of RMM are too far away from the critical area and therefore are not representative for sitespecific processes. For example, recent work has illustrated the importance of the sensor position in the field in defining system performance (Sättele et al., 2013).

3. Current EWSs typically measure simple proxies of RMMs rather than the critical slope properties. Sensors typically measure environmental variables that affect the trigger process (e.g., rainfall, precipitation) but not the critical slope properties controlling the initiation of triggering (suction or pore water pressure, soil water content and saturation profiles, depth and stratigraphy of the snow cover). Depending on these variable dispositions, slope failure may occur in response to a large variety of precipitation intensity and duration (Zimmermann et al., 1997). Accordingly, the monitoring of precipitation may induce considerable uncertainty for the warning procedure.

4. Precursors of imminent hazards are scarcely considered in current EWSs. Triggering failure will usually be preceded by the development of local strains along the expected shear zones, which may occur gradually or as specific events very close to the time when the mass is triggered. So far, the relationship between these "precursor events" and the time and size of mass release is poorly understood. In some cases, there is insufficient precursor activity and/or inadequate time between the precursors and the rapid movement (e.g., Kean et al., 2011).

5. Current EWSs do not account for uncertainty in an appropriate way. Uncertainties are inherent to all EWSs. Accounting for and managing uncertainty represents one of the main challenges for EWSs. Uncertainties are related to the prediction/recognition of the triggering as well as to the transition of the mass and thus directly affect success or failure of warning and effective risk reduction (avoidance of loss of life or damage). Unfortunately, uncertainty estimates (e.g., ensemble forecasts that give representative samples of the possible future states) are often missing, or only weakly represented, in current EWSs. Furthermore, uncertainties are difficult to communicate to authorities and to the population that potentially may be affected. New probabilistic models for the occurrence of RMM (e.g., Berti et al., 2012) may be helpful tools in this respect.

6. Many current EWSs do not include estimates of how mobile the predicted RMM will be (i.e., how fast and how far will the landslides travel). Such information, however, is essential for defining the endangered area and for taking appropriate measures within the available time. For example, snow avalanches do often not reach the endangered roads or trail section after detection of an event, and thus false alarms and associated costs for intervention measures are produced.

\section{Current innovations in modeling and observation of RMM}

To overcome the above-mentioned limitations of EWSs, innovative approaches - partly from other disciplines - have been introduced into the research of RMM. New models and observation techniques are currently being developed that can be combined into an integral system that makes use of complementary information from various sources. In the following we discuss examples of recent developments and link them to the above-stated deficits.

\subsection{From simple thresholds to patterns: the example of precipitation}

Accurate and timely knowledge of precipitation is a key for warning about impending RMM. The inherent problem with measuring and predicting precipitation is its large variability over a wide range of spatial and temporal scales. This variability needs to be properly taken into account in EWSs. Traditional ways of monitoring precipitation using only a few rain gauges over an entire catchment is far from optimal because rain gauges have a very limited spatial representativeness. Weather radar provides precipitation estimates that are more representative over large areas and can be used to better predict the distribution of RMMs within a given area (Crosta and Frattini, 2003; Chiang and Chang, 2009; Jorgensen et al., 2011). Unfortunately, radar data are often too coarse to be used directly in EWSs. New stochastic disaggregation techniques (Schleiss and Berne, 2012) are currently being developed that allow rain rate fields collected by radar or simulated by numerical weather prediction models to be downscaled while preserving their main statistical properties (e.g., distribution, intermittency and structure). The intermittent nature of precipitation has been shown to have a profound impact on its variability (Schleiss et al., 2014). The proposed stochastic method can be used to generate large numbers of different outcomes for a single input field. These scenarios can then be applied to landscape models (Von Ruette et al., 2014) and used to determine the most vulnerable areas for a particular rain event. It can also be used to derive new rainfall thresholds for EWSs and help to identify critical rainfall patterns that could trigger rapid mass movements.

\subsection{Spatial representation of precipitation data in EWSs}

Inclusion of additional sources of information (e.g., from private weather services or hydropower companies) could partly 
fill in important gaps in the data, thereby reducing the problem of limited representativeness of local rain gauges. Furthermore, the increasing availability of satellite-derived precipitation products at regional scales has driven important progress toward landslide nowcast assessments and warning. Several products of the Tropical Rainfall Measurement Mission (TRMM) have been improved over the past years and have been evaluated for landslide warning purposes (Hong et al., 2007; Kirschbaum et al., 2012). Limitations arise from reduced accuracy of precipitation records at time intervals, which may be relatively long (e.g., $3 \mathrm{~h}$ ) in comparison to local intense rainfall trigger conditions, and also from accuracy issues over complex mountain topography (Scheel et al., 2011).

\subsection{New techniques for in situ and remote observations of critical slopes}

Prediction of the triggering of debris flows remains a significant challenge, however, because it is rarely possible logistically or financially to install instruments at all possible failure locations. Broadband seismic networks, most commonly used for earthquake or other geophysical research, have recently been used to document snow avalanches (van Herwijnen and Schweizer, 2011b; Lacroix et al., 2012) and landslides as well as the transformation of landslides into a debris flow (Burtin et al., 2014). Recent work on snow avalanches suggests that an early warning based on accurate and near real-time avalanche activity monitoring is possible (Schweizer and van Herwijnen, 2013). Indeed, before periods of high wet-snow avalanche activity, the waiting time between avalanches clearly decreased towards peak avalanche activity. Prerequisites for applying the waiting time approach as an operational early warning tool are near real-time data transmission and automatic signal detection. We expect that this technology will be improved through the elaboration of seismic triggering thresholds and by cataloging seismic signals typically produced by various types of landslides, thereby eventually making it possible to automate the detection. Many examples already exist, e.g., typical seismic properties have already been described for landslides (e.g., Suriñach et al., 2005; La Rocca et al., 2004; Ekström and Stark, 2013), debris flows (Burtin et al., 2009) and snow avalanches (e.g., Suriñach et al., 2005); however, the density of seismic monitoring instruments must be relatively large to accurately identify the initiation zone (e.g., on the order of one station per square kilometer was used by Burtin et al., 2014), and algorithms to identify mass movements automatically have not, to the best of our knowledge, been developed or tested for their applicability to early warning. Of course, it will be necessary to identify precursor seismic signals for early warning, or at least the initial onset of movement, prior to the release of the main body of material.

Recent advances in portable ground-based radar interferometry using a new tripod-mounted radar instrument (Caduff et al., 2011) have reduced the amount of time necessary to determine the spatial distribution of movement of a hillslope by accounting for the influence of atmospheric disturbances on the radar signal, thereby increasing the usefulness of ground-based radar interferometry for early warning. For example, it was possible to measure rates of hillslope movement of $3 \mathrm{~mm}$ per day for a landslide with an estimated volume of $500000 \mathrm{~m}^{3}$ at the Illgraben catchment (Canton VS, Switzerland). The radar interferometer can measure from several locations to permit construction of 3-D movement vectors of landslides. While the use of ground-based radar for measuring slope deformation has become relatively common (Caduff et al., 2015), work still needs to be done to develop general algorithms to process the radar data automatically to provide real-time warning of movement exceeding a user-defined threshold, especially during periods of strong atmospheric disturbance (Caduff et al., 2011).

\subsection{Detection of precursors}

Before a destabilized soil or snow mass is released, the progressive character of slip plane formation comprises many small-scale mechanical failure events, such as the destruction of mechanical bonding agents (biological fibers, cemented grain contacts, plant roots, ice crystals), friction between grains, redistribution of internal stresses or crack formation.

These local mechanical failure events cause release of energy that propagates through the porous medium as an elastic wave that can be measured as acoustic emissions (AE). Signals are generated at a high frequency because of the small size/scale of precursor failure events. Tests with natural soils revealed characteristic frequency ranges between 1 and $100 \mathrm{kHz}$ for acoustic emissions associated with failure (Michlmayr et al., 2012). The range extends towards $1000 \mathrm{kHz}$ for failure in permafrost specimens (Yamamoto and Springman, 2014). Providing the ability to detect single failure events down to the grain scale, acoustic emissions present a mechanical microscope for in situ monitoring of progressive slope failure. Direct shear tests with different synthetic and natural granular media corroborated a coherent link between shear plane formation, micro-mechanical failure events and synchronously observed acoustic emissions (Yamamoto and Springman, 2014; Michlmayr et al., 2013). Theoretical considerations based on granular material dynamics and wave propagation concepts allow the acoustic signature to be modeled and provide potential to interpret measured $\mathrm{AE}$ with respect to the material failure mode.

Acoustic precursory patterns are also investigated for snow avalanche release (Van Herwijnen and Schweizer, 2011a; Reiweger and Schweizer, 2013). Snow slab avalanches are released as the result of crack formation and propagation in a buried weak snowpack layer. Laboratory fracture experiments with snow samples containing a weak snow layer confirmed that acoustic signals originate from within the weak layer (Reiweger et al., 2015). The failure of a weak snow 
layer resembles a progressive transition into a critical state (Johansen and Sornette, 2000) that is manifested by typical power-law statistics. Such power-law behavior was also observed in snow samples, and it was discovered that the distribution of the AE signals changed before, during and after fracture (Reiweger and Schweizer, 2013). A similar change of precursory signals before mass release was also observed (Amitrano et al., 2005; Cohen et al., 2009) and simulated (Lehmann and Or, 2012) for other types of RMM. More specifically, the frequency distribution of the released energy follows a power law with an exponent that changes before the mass release. The validity of power laws in the precursory patterns is also an indication of the progressive material failure that is included in new types of models, as we will discuss in the following section.

\subsection{Assessing and reducing uncertainty related to the triggering process}

Recent advancements have been made in modeling the triggering of rapid mass movements. For example, the change of hydromechanical material properties with increasing water content has been implemented in constitutive mechanical models to better represent the transition of soils from a partially to a fully water-saturated state (Nuth and Laloui, 2008). In this way, potential triggering of landslides can be analyzed in a systematic way by considering matric suction losses induced by rainfall infiltration (e.g., Eichenberger et al., 2013). To this end, ensemble weather forecasts (Molteni et al., 1996) will help assessing a reasonable range of uncertainty for forthcoming hours and days. To reduce uncertainty with respect to simulated water contents, soil wetness patterns can be determined by remote sensing (Finn et al., 2011) or using wireless networks of low-cost water content sensors (Bogena et al., 2007).

There is evidence that the spatial patterns at larger scale, including macro-permeability and the local hydrogeology, are key factors for the initiation of landslides. In a field study on triggering a shallow landslide by intense sprinkling (Springman et al., 2009), it was shown that exfiltration from the bedrock was an important destabilizing factor, whereas zones in which drainage into the bedrock prevented the water table from rising remained stable (Askarinejad, 2013). The field study revealed as well that persisting positive pore pressures and high water saturation in large interconnected regions of the hillslope were required to initiate mass release (Lehmann and Or, 2013).

An additional challenge for physically based landslide triggering models is the abrupt mass release without clear indication of changes at the surface. New landslide triggering models based on a concept of self-organized criticality were developed to simulate abrupt mass release as progressive failure of soils discretized as interconnected soil columns (Lehmann and Or, 2012; Von Ruette et al., 2013). Such models reproduced the concept that during intense rainfall events, "weak" soil (or snow) units and connections can break and a rapid chain reaction culminating in mass release may be initiated. The weakening and local failure of soil (or snow) is modeled explicitly which allows deriving statistics that indicate the rapidly increasing probability of the failure.

\subsection{Use of mass flow models in EWSs to assess mobility of RMM}

Progress in physically based mass flow models is important for several aspects of early warning. The design of an EWS requires understanding of the areas potentially affected by mass movements, especially in downstream areas where lives and infrastructure may be negatively impacted. Such models are based on principles of mass, momentum and energy conservation and many solve the shallow water equations adapted for granular flows and include appropriate resistance terms to describe the flowing friction of a landslide. Examples are RAMMS (Christen et al., 2010), FLO-2D (O'Brien et al., 1993), SPH 2-D (Žic et al., 2014) and DAN-3D (Hungr and McDougall, 2009), which have been applied to a large range of RMM, including ice and rock avalanches, debris flows, lahars or hyperconcentrated flows (e.g., Willenberg et al., 2009; Evans et al., 2009). Coupled or cascading RMM are a particular challenge to EWSs and may include rock or ice avalanche impacts into lakes, generating displacement waves and eventually lake outburst floods. Recent studies have coupled several models to simulate cascading processes and to provide an estimate of areas affected, including the generation of hazard maps as an input to EWS design (Schneider et al., 2014). Lead time for warning is a critical element for EWSs and dynamic mass flow models are able to provide related estimates (Schneider et al., 2014) which can be improved by calibration using local instrumentation such as geophone or flow stage data (e.g., Badoux et al., 2009).

\section{Implementation of innovations into EWSs}

The transition from current limited EWSs to future innovative EWSs implies a number of challenges both to scientists developing the scientific basis and to the natural hazard experts installing and operating such EWSs. Some of these challenges were identified in the framework of the project SafeLand (EU FP7; Michoud et al., 2013), and corresponding strategies were proposed (Intieri et al., 2013). We are convinced that overcoming the following challenges will be essential in order to make significant advances towards effective next-generation EWSs.

Obtaining accurate, real-time high-resolution precipitation information at a reasonable cost still represents a great challenge, especially in areas of complex topography and high relief (e.g., in the Alps), where the visibility of weather radar is strongly impeded. Spaceborne radars (e.g., the dualfrequency radar of the Global Precipitation Mission) provide 
useful precipitation information that complement groundbased data (if available). Fast and automatic disaggregation of ground-based and spaceborne radar data for EWSs also represents a challenging task from the operational point of view and needs to be further investigated.

A fundamental advance in the availability and use of information about the soil, snow and bedrock will be the key for enabling numerical models to be used in operational EWSs. For instance, at present, Switzerland still lacks a soil hydrological map that could be used to derive soil hydraulic properties. The spatial exploration of soil properties relevant for slope instabilities, as well as of the snow cover, requires substantial further development of non-invasive geophysical methods. Such information at the scale of slopes will become essential to translate precipitation fields into maps of water saturation, loads and soil/snow strengths for slope stability models. To ensure reliability of such derived soil-water fields, spatial measurements of water content and water pressure will have to be assimilated. This, for its part, will require considerable innovations in the development of (wireless) sensors and remote-sensing-based methods.

A further challenge will be to develop technical systems to measure precursors at affordable cost. For example, the measurement of acoustic emission precursors in a field setting is today in a fledgling state. Numerous problems must be solved before AE devices become practical tools. For example, the strong attenuation of the high-frequency elastic waves will have to be counteracted. A potential technology to overcome this problem could be fiber-optic AE sensing. Novel data acquisition methods can provide information on elastic waves impinging on a fiber-optic cable with a spatial resolution in the range of a few meters along a distance of several hundreds of meters. Entire transects of a susceptible hillslope may be monitored with this method, and precursory $\mathrm{AE}$ events can be reported from failure-prone sections instantaneously. The feasibility of this technique at field scale will be tested in the near future.

Related to the implementation of future innovative EWSs, a main challenge will be to make the technical system comprehensible and usable by operators. Typical operators of EWSs may have a basic knowledge of the observed processes, but they are probably not scientists or engineers. Automated operation can be dangerous when the person responsible for security can not make a link between an automatically generated value and the process (e.g., warning level red, without knowing which values should generate a red level). The processes are normally too hazardous so that the necessary measures just can be deduced from an automatically generated value (e.g., a warn level). Therefore, interpretation is essential. However, interpretation by locals is only possible if the EWS is not a black box, and clear guidance is provided about how the warning level must be interpreted.

Finally, the key requirement of redundancy and reliability of the technical system remains a difficult task, which is also the case for future EWSs. Current advances in remote sensing, e.g., by satellite-based radar systems, need to be better integrated into operational systems. Recent work in the upper Reuss valley (Switzerland) (Wegmüller et al., 2013), contracted by the Swiss Federal Railways (SBB), has shown that such observations could become a useful complement to ground-based measurements. Not least, the added value of numerical models running in a real-time mode (providing ensemble forecasts) for the redundancy and reliability of technical systems needs to be further explored.

\section{Outlook}

A substantial advance from current to next-generation technical systems for early warning of rapid mass movements will require fundamental investments in basic research, in the dialogue between researchers and EWS operators and in the exploitation and exchange of experiences.

First of all, the basic research related to mechanisms, early detection and prediction of the initiation of rapid mass movements has to be further intensified. A substantial advance can only be achieved in an interdisciplinary setting. Our experiences suggest that most important will be new insights in how local observations - typically of very small scale - can be used to derive, over a short time and with high certainty, a risk estimation for the scale of slopes and regions. In this respect, innovations in the use of (complex) numerical models as a complement to observation systems will be of great importance.

Second, the knowledge increase at the research institutes has to be followed up and influenced by practitioners much more than in the past. A critical review of new research results by those in charge of or operating EWSs will become essential. To this end, the dialogue between practitioners and scientists needs to be strengthened and institutionalized (e.g., Bründl et al., 2004). Establishing a common language will be a non-trivial prerequisite. A regular dialogue between practitioners, engineers and scientists will also help to foster a better understanding of the real problems and needs of operators.

Finally, gaining real experiences with new (prototype) EWSs will be key to developing confidence and reducing skepticism of those making decisions and operating them. To this end, it would be necessary to install pioneer examples of functioning EWSs that both constitute a real case of emergency with institutional need for action and which can be used to test innovations. In the following paragraphs we sketch how such a novel EWS could be designed and work for shallow landslides.

For early recognition of shallow landslides, the concept would aim at detecting precursors occurring at a limited spatial scale, related to release of elastic energy in a frequency range defined as acoustic emission. Attenuation of released energy in the porous media requires a high spatial density of sensors across a long distance, a condition that can be met 
(a) Invariant input

(b) Changing input

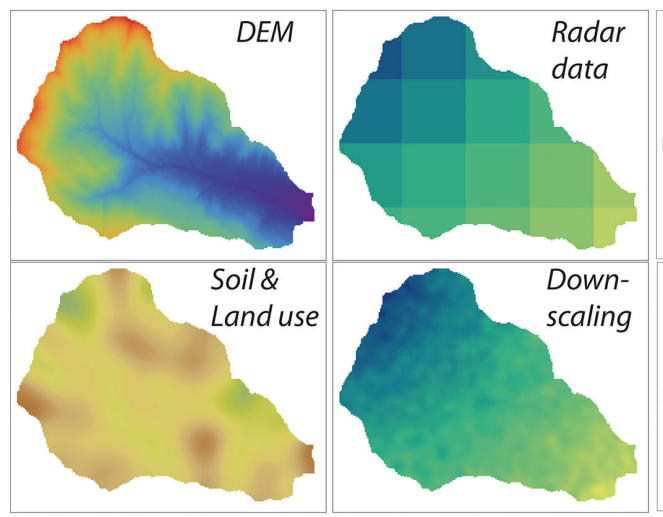

(c) Model adjustment

(d) Landslide forecast

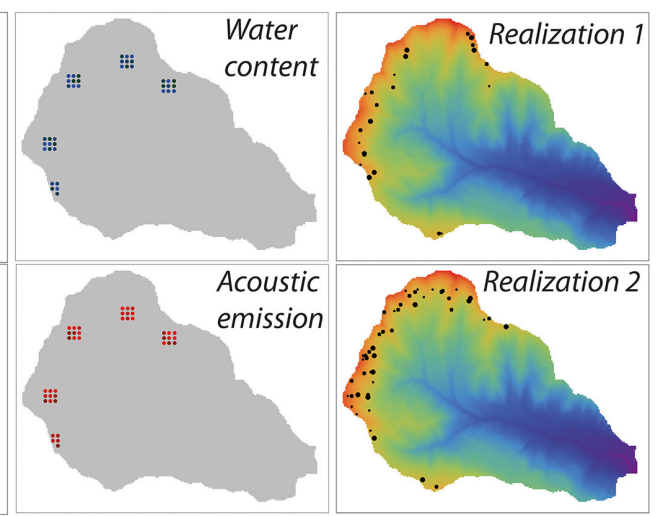

Figure 3. Example of possible future landslide forecasting system at catchment scale. Based on a digital elevation model (DEM) and information on soil type and land use (a), the triggering model will compute the loading and failure patterns using rainfall data (radar values downscaled by disaggregation model) as input (b). Water content and mechanical precursor values measured with a network of wireless sensors (c) can be compared to model predictions. In a series of model simulations the time, position and volume of the landslide triggering will be predicted. The ensemble of several realizations will be used to forecast the triggering (d).

by new fiber-optic-based acoustic emission sensors (Parker et al., 2014). With a cable installed in loops on a hillslope above a residential area or along a traffic pathway in steep terrain, small-scale mechanical events (shearing particles, breaking roots and cementing agents) would be captured at appropriate scale (meters and seconds) by measuring amplitudes of AE signals, the waiting time in between and the frequency magnitude statistics collected over a time interval. As soon as these signal properties start to change towards more frequent events with high amplitudes, the system converges to a critical state and a warning would be released.

For a larger area (catchment scale) where continuous measurements and monitoring of precursors at high spatial resolution are not possible, local AE measurements would be combined with model predictions. For the modeling, information on surface terrain (digital elevation model), land use, soil type and soil depth would be used. As stated in the previous section, reliable information on soil type and depth is currently missing and progress along the lines of soil depth modeling or deducing information from remote sensing data (Shafique et al., 2011) is mandatory. Assuming that this "time invariant" information is available in the near future, it would be used to initiate a triggering model computing the evolution of water content distribution and resulting mechanical loading and failure processes, using various time series of key properties like rainfall intensity, water content and precursor activity as input data (Fig. 3). With respect to rainfall data the prototype system would distinguish between measurements (radar data) with limited spatial resolution and the downscaling to high spatial resolution with appropriate disaggregation model. For each modeled time step the downscaled rainfall data would be used as input for the loading of the system. By maintaining a network of wireless sensors measuring water content and failure precursors (based on acoustic emission) the hydromechanical state at selected spots would be compared to model predictions and the measured values would be used to recalibrate the model. The landslide model would then compute a series of realizations covering the uncertainty in input parameters. The resulting ensemble of predicted outcome would be used to make statements on the risk of landslide triggering (including information on location, time and volume of failure occurrence). Such prototype EWSs could then be exploited for the training of practitioners, students and decision-makers. A systematic collection of negative experiences from technical failures, false interpretations and wrong decisions in emergency measures will help further in improving future systems.

Acknowledgements. This paper is a result of a workshop in January 2013 within the framework of the project TRAMM Triggering of Rapid Mass Movements in Steep Terrain - financed by the ETH Competence Centre of Environment and Sustainability (CCES). We are grateful to the valuable discussion and remarks of Florian Frank (WSL), Jérome Faillettaz (ETH Zürich), Ueli Gruner (Kellerhals und Haefeli AG), Daniel Tobler (Geotest AG), Nils Hählen and Jörg Häberle (both at the Department of Natural Hazards of the Canton Berne).

Edited by: F. Guzzetti

Reviewed by: J. Coe and one anonymous referee 


\section{References}

Amitrano, D., Grasso, J. R., and Senfaute, G.: Seismic precursory patterns before a cliff collapse and critical point phenomena, Geophys. Res. Lett., 32, L08314, doi:10.1029/2004GL022270, 2005.

Askarinejad, A.: Failure mechanisms in unsaturated silty sand slopes triggered by rainfall, ETH-Diss No. 21423, ETH Zurich, Zurich, 246 pp., doi:10.3929/ethz-a-010002526, 2013.

Bacchini, M. and Zannoni, A.: Relations between rainfall and triggering of debris-flow: case study of Cancia (Dolomites, Northeastern Italy), Nat. Hazards Earth Syst. Sci., 3, 71-79, doi:10.5194/nhess-3-71-2003, 2003.

Badoux, A., Graf, C., Rhyner, J., Kuntner, R., and McArdell, B. W.: A debris-flow alarm system for the Alpine Illgraben catchment: design and performance, Nat. Hazards, 49, 517-539, 2009.

Baum, R. L. and Godt, J. W.: Early warning of rainfall-induced shallow landslides and debris flows in the USA, Landslides, 7, 259272, 2010.

Bell, R., Mayer, J., Pohl, J., Greiving, S., and Glade, T.: Integrative Frühwarnsysteme für gravitative Massenbewegungen (ILEWS), Monitoring, Implementierung, Klartext Verlag, Essen, 2010.

Berti, M., Martina, M. L. V., Franceschini, S., Pignone, A., Simoni, A., and Pizziolo, M.: Probabilistic rainfall thresholds for landslide occurrence using a Bayesian approach, J. Geophys. Res., 117, F04006, doi:10.1029/2012JF002367, 2012.

Bogena, H. R., Huisman, J. A., Oberdörster, C., and Vereecken, H.: Evaluation of a low-cost soil water content sensor for wireless network applications, J. Hydrol., 344, 32-42, 2007.

Bründl, M., Etter, H.-J., Steiniger, M., Klingler, Ch., Rhyner, J., and Ammann, W. J.: IFKIS - a basis for managing avalanche risk in settlements and on roads in Switzerland, Nat. Hazards Earth Syst. Sci., 4, 257-262, doi:10.5194/nhess-4-257-2004, 2004.

Burtin, A., Bollinger, L., Cattin, R., Vergne, J., and Nabelek, J. L.: Spatiotemporal sequence of Himalayan debris flow from analysis of high-frequency seismic noise, J. Geophys. Res.-Earth Surf., 114, F04009, doi:10.1029/2008JF001198, 2009.

Burtin, A., Hovius, N., McArdell, B. W., Turowski, J. M., and Vergne, J.: Dynamic links between channel and hillslopes revealed by seismic monitoring, Earth Surf. Dynam., 2, 21-33, 2014.

Caduff, R., Kos, A., Schlunegger, F., McArdell, B. W., and Wiesmann, A.: Terrestrial Radar Interferometric Measurement of Hillslope Deformation and Atmospheric Disturbances in the Illgraben Debris-Flow Catchment, Switzerland, IEEE Geosci. Remote Sens. Lett., 11, 434-438, 2011.

Caduff, R., Schlunegger, F., Kos, A., and Wiesmann, A.: A review of terrestrial radar interferometry for measuring surface change in the Geosciences, Earth Surf. Process. Landf., 40, 208-228, doi:10.1002/esp.3656, 2015.

Capparelli, G. and Tiranti, D.: Application of the MoniFLaIR early warning system for rainfall-induced landslides in Piedmont region (Italy), Landslides, 7, 401-410, 2010.

Chan, R. K. S. and Pun, W. K.: Landslip warning system in Hong Kong, in: Geotechnical Instrumentation News, BiTech Publishers Ltd., Richmond, BC, Canada, available at: http://www.bitech. ca/instrumentation_news.php (last access: November 2014), 3335, 2004.

Chang, S. Y.: Evaluation of a system for detecting debris flows and warning road traffic at bridges susceptible to debris-flow hazard, in: Debris-flow Hazard Mitigation: Mechanics, Prediction, and Assessment, edited by: Rickenmann, D. and Chen, C., Millpress, Rotterdam, ISBN 907701778X, 731-742, 2003.

Chen, C.-Y., Chen, T.-C., Yu, F.-C., Yu, W.-H., and Tseng, C.-C.: Rainfall duration and debris-flow initiated studies for real-time monitoring, Environ. Geol., 47, 715-724, 2005.

Chiang, S.-H. and Chang, K.-T.: Application of radar data to modeling rainfall-induced landslides, Geomorphology, 103, 299-309, 2009.

Chleborad, A. F., Baum, R. L., and Godt, J. W.: A prototype system for forecasting landslides in the Seattle, Washington, Area, in: Engineering geology and landslides of the Seattle, edited by: Baum, R. L., Godt, J. W., and Highland, L. M., Washington, area: Geological Society of America Reviews in Engineering Geology v. XX, 103-120, doi:10.1130/2008.4020(06), 2008.

Christen, M., Kowalski, J., and Bartelt, P.: RAMMS: Numerical simulation of dense snow avalanches in three-dimensional terrain, Cold Reg. Sci. Technol., 63, 1-14, 2010.

Cohen, D., Lehmann, P., and Or, D.: Fiber bundle model for multiscale modeling of hydromechanical triggering of shallow landslides, Water Resour. Res., 45, W10436, doi:10.1029/2009WR007889, 2009.

Cole, K. and Davis, G. M.: Landslide warning and emergency planning systems in West Dorset, England, in: Instability. Planning and Management, edited by: McInnes, R. G. and Jakeways, J., Thomas Telford Publishing, London, UK, ISBN: 0727731327, 463-470, 2002.

Crosta, G. B. and Frattini, P.: Distributed modelling of shallow landslides triggered by intense rainfall, Nat. Hazards Earth Syst. Sci., 3, 81-93, doi:10.5194/nhess-3-81-2003, 2003.

Egger, P. and Mair, V.: Innovative measures to reduce dangers using the Grissian Torrent as an example, J. Wildbach Lawinen Eros. Steinschlag., 161, available at: http://www.wlv-austria.at/ journal_archivartikel.php? ausgabe $=29 \&$ artausgabe $=296$ (last access: November 2014), 2009.

Eichenberger, J., Ferrari, A., and Laloui, L.: Early warning thresholds for partially saturated slopes in volcanic ashes, Comput. Geotech., 49, 79-89, 2013.

Ekström, G. and Stark, C. P.: Simple Scaling of Catastrophic Landslide Dynamics, Science, 339, 1416-1419, 2013.

Evans, S. G., Tutubalina, O. V., Drobyshev, V. N., Chernomorets, S. S., McDougall, S., Petrakov, D. A., and Hungr, O.: Catastrophic detachment and high-velocity long-runout flow of Kolka Glacier, Caucasus Mountains, Russia in 2002, Geomorphology, 105, 314-321, 2009.

Eyer, W., Gubler, H. U., Keusen H. R., and Naef, O.: Frühwarndienste - Stand der Kenntnisse und Anwendungsbeipiele, FAN Forstliche Arbeitsgruppe, Glarus, Switzerland, 1998.

Finn, M., Lewis, M. D., Bosch, D., Giraldo, M., Yamamoto, K., Sullivan, D., and Kincaid, R.: Remote sensing of soil moisture using airborne hyperspectral data, GISci. Remote Sens., 48, 522540, 2011.

Flentje, P., Chowdhury, R. N., Tobin, P., and Brizga, V.: Towards real-time landslide risk management in an urban area, in: Landslide Risk Management, edited by: Hungr, O., Fell, R., Couture, R., and Eberhardt, E., Proceedings of the International Conference on Landslide Risk Management, 31 May-4 June 2005, Vancouver, Canada, 741-751, 2005. 
Forsttechnischer Dienst für Wildbach- und Lawinenverbauung: Frühwarn- und Monitoringsysteme in Österreich, Zustandsbericht 2008, Entscheidungshilfe: Frühwarnsystem. Forsttechnischer Dienst für Wildbach- und Lawinenverbauung, Sektion Salzburg, Fachschwerpunkt Frühwarn- und Monitoringsysteme, Salzburg, Austria, 90 pp., 2008.

Glantz, M. H.: Early warning system: Does and Don't, Report of Workshop 20-23 October 2003, Shanghai, China, 76 pp., 2003.

Glade, T. and Nadim, F.: Early warning systems for natural hazards and risks, Nat. Hazards, 70, 1669-1671, 2014.

Gubler, H.: Five years experience with avalanche-, mudflow-, and rockfall-alarm systems in Switzerland, in: Proceedings of the international snow science workshop (ISSW), Big Sky, Montana, 2000.

Guzzetti, F., Peruccacci, S., Rossi, M., and Stark, C. P.: The rainfall intensity-duration control of shallow landslides and debris flows: an update, Landslides, 5, 3-17, 2008.

Hegg, C. and Rhyner, J.: Warnung bei aussergewöhnlichen Naturereignissen. Forum für Wissen, Swiss Federal Research Institute WSL, Birmensdorf, ISSN 1021-2256, 96 pp., 2007.

Heil, B., Petzold, I., Romang, H., and Hess, J.: The common information platform for natural hazards in Switzerland, Nat. Hazards, 70, 1673-1687, 2014.

Honda K., Aadit, S., Rassarin, C., Nguyen, D. H., Hiroshi, S., Teuku, F. F., Dwikorita, K., and Kyoji, S.: Landslide early warning system for rural community as an application of Sensor Asia. World Conference on Agricultural Information and IT, IAALD AFITA WCCA, 24-27 August 2008 at Tokyo University of Agriculture, Tokyo, 283-288, 2008.

Hong, Y., Adler, R. F., and Huffman, G.: An Experimental Global Prediction System for Rainfall-Triggered Landslides Using Satellite Remote Sensing and Geospatial Datasets, IEEE Trans. Geosci. Remote Sens., 45, 1671-1680, 2007.

Huggel, C., Khabarov, N., Obersteiner, M., and Ramírez, J. M.: Implementation and integrated numerical modeling of a landslide early warning system: a pilot study in Colombia, Nat. Hazards, 52, 501-518, 2010.

Hungr, O. and McDougall, S.: Two numerical models for landslide dynamic analysis, Comput. Geosci., 35, 978-992, 2009.

Intrieri, E., Gigli, G., Mugnai, F., Fanti, R., and Casagli, N.: Design and implementation of a landslide early warning system, Eng. Geol., 147-148, 124-136, 2012.

Intrieri, E., Gigli, G., Casagli, N., and Nadim, F.: Brief communication "Landslide Early Warning System: toolbox and general concepts", Nat. Hazards Earth Syst. Sci., 13, 85-90, doi:10.5194/nhess-13-85-2013, 2013.

Itakura, Y., Koga, Y., Takahama, J., and Nowa, Y.: Acoustic detection sensor for debris flow, in: Debris-flow hazards mitigation, edited by: Chen, C., ASCE, American Society of Civil Engineers, New York, NY, 747-756, 1997.

Jakob, M., Holm, K., Lange, O., and Schwab, J. W.: Hydrometeorological thresholds for landslide initiation and forest operation shutdowns on the north coast of British Columbia, Landslides, 3, 228-238, 2006.

Jakob, M., Owen, T., and Simpson, T.: A regional real-time debris-flow warning system for the District of North Vancouver, Canada, Landslides, 9, 165-178, 2012.

Johansen, A. and Sornette, D.: Critical ruptures, Eur. Phys. J. B, 18, 163-181, 2000.
Jorgensen, D. P., Hanshaw, M. N., Schmidt, K. M., Laber, J. L., Staley, D. M., Kean, J. W., and Restrepo, P. J.: Value of a dualpolarized gap-filling radar in support of southern California postfire debris-flow warnings, J. Hydrometeorol., 12, 1581-1595, 2011.

Kean, J. W., Staley, D. M., and Cannon, S. H.: In situ measurements of post fire debris flows in southern California: Comparisons of the timing and magnitude of 24 debris flow events with rainfall and soil moisture conditions, J. Geophys. Res.-Earth Surf., 116, F04019, doi:10.1029/2011JF002005, 2011.

Keefer, D. K., Wilson, R. C., Mark, R. K., Brabb, E. E., Brown, W. M., Ellen, S. D., Harp, E. L., Wieczorek, G. F., Alger, C. S., and Zatkin, R. S.: Real-time landslide warning during heavy rainfall, Science, 238, 921-925, 1987.

Kirschbaum, D. B., Adler, R., Hong, Y., Kumar, S., Peters-Lidard, C., and Lerner-Lam, A.: Advances in landslide nowcasting: evaluation of a global and regional modeling approach, Environ. Earth Sci., 66, 1683-1696, 2012.

Lacroix, P., Grasso, J., Roulle, J., Giraud, G., Goetz, D., Morin, S., and Helmstetter, A.: Monitoring of snow avalanches using a seismic array: Location, speed estimation, and relationships to meteorological variables, J. Geophys. Res.-Earth Surf., 117, F01034, doi:10.1029/2011JF002106, 2012.

La Rocca, M., Galluzo, D., Saccorotti, G., Tinit, S., Cimini, G. B., and Del Pezzo, E.: Seismic signals associated with landslides and with a tsunami at Stromboli Volcano, Italy, Bull. Seismol. Soc. Am., 94, 1850-1867, 2004.

Lehmann, P. and Or, D.: Hydromechanical triggering of landslides: From progressive local failures to mass release, Water Resour. Res., 48, W03535, doi:10.1029/2011WR010947, 2012.

Lehmann, P. and Or, D.: Effect of wetness patchiness on evaporation dynamics from drying porous surfaces, Water Resour. Res., 49, 8250-8262, 2013.

Lehning, M., Bartelt, P., Brown, B., Russi, T., Stöckli, U., and Zimmerli M.: A network of automatic weather and snow stations and supplementary model calculations providing snowpack information for avalanche warning, in: Proceedings of the International Snow Science Workshop "a Merging of Theory and Practice", September 1998, Washington State Departement of Transportation, Sunriver, Oregon, Seattle, Washington, 225-233, 1998.

Loew, S., Gitschig, V., Moore, J. R., and Keller-Signer, A.: Monitoring of potentially catastrophic rockslides, in: Landslides and Engineered Slopes: Protecting Society through Improved Understanding, edited by: Eberhardt, E., Froese, C., Turner, K., and Leroueil, S., Taylor \& Francis Group, London, 101-116, 2012.

Michlmayr, G., Cohen, D., and Or, D.: Sources and characteristics of acoustic emissions from mechanically stressed geologic granular media - A review, Earth-Sci. Rev., 112, 97-114, 2012.

Michlmayr, G., Cohen, D., and Or, D.: Shear-induced force fluctuations and acoustic emissions in granular material, J. Geophys. Res.-Solid Earth, 118, 6086-6098, 2013.

Michoud, C., Bazin, S., Blikra, L. H., Derron, M.-H., and Jaboyedoff, M.: Experiences from site-specific landslide early warning systems, Nat. Hazards Earth Syst. Sci., 13, 2659-2673, doi:10.5194/nhess-13-2659-2013, 2013.

Molteni, F., Buizza, R., Palmer, T. N., and Petroliagis, T.: The ECMWF ensemble prediction system: Methodology and validation, Q. J. Roy. Meteorol. Soc., 122, 73-119, 1996. 
NOAA-USGS Debris Flow Task Force: NOAA-USGS debris-flow warning system. Final report, US Geological Survey Circular 1283, US Geological Survey, Reston, Virginia, USA, p. 47, available at: http://pubs.usgs.gov/circ/2005/1283/pdf/Circular1283. pdf (last access: November 2014), 2005.

Nuth, M. and Laloui, L.: Advances in modelling hysteretic water retention curve in deformable soils, Comput. Geotech., 35, 835844, 2008.

O'Brien, J., Julien, P., and Fullerton, W.: Two-Dimensional Water Flood and Mudflow Simulation, J. Hydraul. Eng., 119, 244-261, 1993.

Ortiago, J. A. R., Justi, M. G., D’Orsi, R., and Brito, H.: RioWatch 2001: the Rio de Janeiro landslide alarm system, Proc. 14th Southeast Asian Geotechnical Conference, edited by: Ho and Li, Hong Kong, Balkema, 3, 237-241, 2001.

Panziera, L., Germann, U., Gabella, M., and Mandapaka, P. V.: NORA-Nowcasting of Orographic Rainfall by means of Analogues, Q. J. Roy. Meteorol. Soc., 137, 2106-2123, 2011.

Parker, T., Shatalin, S., and Farhadiroushan, M: Distributed Acoustic Sensing - a new tool for seismic applications, First Break, 32, 61-69, 2014.

Reiweger, I. and Schweizer, J.: Measuring acoustic emissions in an avalanche starting zone to monitor snow stability, in: Proceedings ISSW 2013, edited by: Naaim-Bouvet, F., Durand, Y., and Lambert, R., International Snow Science Workshop, Grenoble, France, 7-11 October 2013. ANENA, IRSTEA, Météo-France, Grenoble, France, 942-944, 2013.

Reiweger, I., Mayer, K., Steiner, K., and Dual, J.; Schweizer, J.: Measuring and localizing acoustic emission events in snow prior to fracture, Cold Reg. Sci. Technol., 110, 160-169, 2015.

Rhyner J.: Lawinenwarnung Schweiz - Komponenten eines bewähren Systems, in: Warnung bei aussergewöhnlichen Naturereignissen, edited by: Hegg, C. and Rhyner, J., Forum für Wissen 2007, Swiss Federal Research Institute WSL, Birmensdorf, Switzerland, 91-92, 2007.

Sättele, M. and Meier, L.: Elektronisch Warnen, in: Achtung Naturgefahr, TEC21, Nr. 31-32, espazium, Zurich, Switzerland, 2013.

Sättele, M., Bründl, M., and Straub, D.: A classification of warning system for natural hazards, in: 10th International Probabilistic Workshop, edited by: Moormann, C., Huber, M., and Proske, D., Stuttgart: Institut für Geotechnik der Universität Stuttgart, 257270, 2012.

Sättele, M., Bründl, M., and Straub, D.: Bayesian networks to quantify the reliability of a debris flow alarm system, in: Safety, Reliability, Risk and Life-cycle Performance of Structures and Infrastructures, edited by: Deodatis, G., Ellingwood, B. R., and Frangopol, D. M., Taylor \& Francis Group, London, UK, 2013.

Scheel, M. L. M., Rohrer, M., Huggel, Ch., Santos Villar, D., Silvestre, E., and Huffman, G. J.: Evaluation of TRMM Multisatellite Precipitation Analysis (TMPA) performance in the Central Andes region and its dependency on spatial and temporal resolution, Hydrol. Earth Syst. Sci., 15, 2649-2663, doi:10.5194/hess-15-2649-2011, 2011.

Schleiss, M. and Berne, A.: Stochastic Space-Time Disaggregation of Rainfall into DSD fields, J. Hydrometeorol., 13, 1954-1969, 2012.
Schleiss, M., Chamoun, S., and Berne A.: Non-stationarity in intermittent rainfall: the "dry drift", J. Hydrometeorol., 15, 11891204, 2014.

Schneider, D., Huggel, C., Cochachin, A., Guillén, S., and García, J.: Mapping hazards from glacier lake outburst floods based on modelling of process cascades at Lake 513, Carhuaz, Peru, Adv. Geosci., 35, 145-155, 2014,

http://www.adv-geosci.net/35/145/2014/.

Segoni, S., Battistini, A., Rossi, G., Rosi, A., Lagomarsino, D., Catani, F., Moretti, S., and Casagli, N.: Technical Note: An operational landslide early warning system at regional scale based on space-time variable rainfall thresholds, Nat. Hazards Earth Syst. Sci. Discuss., 2, 6599-6622, doi:10.5194/nhessd-2-6599-2014, 2014.

Shafique, M., van der Meijde, M., and Ullah, S.: Regolith modeling and its relation to earthquake induced building damage: A remote sensing approach, J. Asian Earth Sci., 42, 65-75, 2011.

Springman, S. M., Kienzler, P., Casini, F., and Askarinejad, A.: Landslide triggering experiment in a steep forested slope in Switzerland, Proceedings of the 17th International Conference on Soil Mechanics and Geotechnical Engineering, edited by: Hamza, M., Shahien, M., and El-Mossallamy, Y., Alexandria, Egypt, doi:10.3233/978-1-60750-031-5-1698, 2009.

Springman, S. M., Askarinejad, A., Casini, F., Friedel, S., Kienzler, P., Teysseire, P., and Thielen, A.: Lessons learnt from field tests in some potentially unstable slopes in Switzerland, Acta Slovenica Geotech., 1, 5-29, 2012.

Schweizer, J. and van Herwijnen, A.: Can near real-time avalanche occurrence data improve avalanche forecasting?, in: Proceedings ISSW 2013, edited by: Naaim-Bouvet, F., Durand, Y., and Lambert, R., International Snow Science Workshop, Grenoble, France, 7-11 October, ANENA, IRSTEA, Météo-France, Grenoble, France, 195-198, 2013.

Suriñach, E., Vilajosana, I., Khazaradze, G., Biescas, B., Furdada, G., and Vilaplana, J. M.: Seismic detection and characterization of landslides and other mass movements, Nat. Hazards Earth Syst. Sci., 5, 791-798, doi:10.5194/nhess-5-791-2005, 2005

Tobler, D., Kuli, I., and Hählen, N.: Hazard management in a Debris Flow Affected Area - The Spreitgraben in Central Switzerland. Extended Abstract, International Disaster and Risk Conference, Global Risk Forum, August 2012, Davos, 2012.

UNEP (United Nations Environment Programme): Early Warning Systems: A State of the Art Analysis and Future Directions. Division of Early Warning and Assessment (DEWA), United Nations Environment Programme (UNEP), Nairobi, ISBN: 978-92-8073263-4, 2012.

UN/ISDR: Global Survey of Early Warning Systems: An assessment of capacities, gaps and opportunities towards building a comprehensive global early warning system for all natural hazards, available at: http://www.unisdr.org/2006/ppew/info-resources/ewc3/

Global-Survey-of-Early-Warning-Systems.pdf (last access: November 2014), 2006.

Van Herwijnen, A. and Schweizer, J.: Seismic sensor array for monitoring an avalanche start zone: design, deployment and preliminary results, J. Glaciol., 57, 267-276, 2011a.

Van Herwijnen, A. and Schweizer, J.: Monitoring avalanche activity using a seismic sensor, Cold Reg. Sci. Technol., 69, 165-176, $2011 b$. 
Villagrán de León, J. C., Pruessner, I., and Breedlove, H.: Alert and Warning Frameworks in the Context of Early Warning Systems. A Comparative Review. Intersections No. 12. Bonn: United Nations University Institute for Environment and Human Security, 2013.

Von Ruette, J., Lehmann, P., and Or, D.: Rainfall-triggered shallow landslides at catchment scale - threshold mechanics-based modeling for abruptness and localization, Water Resour. Res., 49, 6266-6285, 2013.

Von Ruette, J., Lehmann, P., and Or, D.: Effects of rainfall spatial variability and intermittency on shallow landslide triggering patterns at a catchment scale, Water Resour. Res., 50 , 7780-7799, doi:10.1002/2013WR015122, 2014.

Wegmüller, U., Strozzi, T., Gruner, U., Gisler, C., and Hauser, M.: Verschiebungsmessungen mittels Satellitenradar im Urner Reusstal oberhalb der Nord-Süd-Verkehrsachse im Zeitraum 1992-2010. Swiss Bull. angew. Geol., 18, 139-153, 2013.
Willenberg, H., Eberhardt, E., Loew, S., McDougall, S., and Hungr, O.: Hazard assessment and runout analysis for an unstable rock slope above an industrial site in the Riviera valley, Switzerland, Landslides, 6, 111-116, 2009.

Yamamoto, Y. and Springman, S. M.: Axial compression stress path tests on artificial frozen soil samples in a triaxial device at temperatures just below $0{ }^{\circ} \mathrm{C}$. Can. Geotech. J., 51, 1178-1195, doi:10.1139/cgj-2013-0257, 2014.

Žic, E., Arbanas, Ž., Bićanić, N., and Ožanić, N.: A model of mudflow propagation downstream from the Grohovo landslide near the city of Rijeka (Croatia), Nat. Hazards Earth Syst. Sci., 15, 293-313, doi:10.5194/nhess-15-293-2015, 2015.

Zimmermann, M., Mani, P., and Romang, H., Magnitude-frequency aspects of alpine debris flows, Ecol. Geol. Helv., 90, 415-420. 1997. 